\title{
Intuitive Approach to use Intelligent Database for Prediction
}

\author{
Prateek Bhatia \\ Northern India Engineering \\ College, \\ Guru Gobind Singh \\ Indraprastha University \\ New Delhi
}

\author{
Nakul Khurana \\ Northern India Engineering \\ College, \\ Guru Gobind Singh \\ Indraprastha University \\ New Delhi
}

\author{
Neha Sharma \\ Northern India Engineering \\ College, \\ Guru Gobind Singh \\ Indraprastha University \\ New Delhi
}

\begin{abstract}
The concept of Intelligent Databases was introduced in 1980 's, as expectations from the conventional databases had increased over the time. A database which could manage information on its own was much anticipated. Over the years, there has been significant development and advances in this field. Different approaches of integrating AI/DB to form an Intelligent Database have been introduced from time to time. The underlying concepts that have been proved separately as well as jointly, are the prime motivations and foundations of this paper. In addition to this, the use of artificial intelligence for prediction/forecasting has led to the conceptual approach of putting together more than two technologies for the betterment of not only our future, but for the next generation of computing. Few different approaches to AI/DB integration have been studied and reported in this paper.
\end{abstract}

KEYWORDS - Database, Artificial Intelligence, Prediction, IDI

\section{INTRODUCTION}

Artificial Intelligence is simply an art creating intelligence in machines. Intelligence is the computational part of the ability to achieve goals in the world. In 1947, Alan Turing was the first to introduce Artificial Intelligence to the world and hence The Turing Test.

Alan Turing's 1950 article Computing Machinery and Intelligence discussed conditions for considering a machine to be intelligent.[1] $\mathrm{He}$ argued that if the machine could successfully pretend to be human to a knowledge-able observer then you certainly should consider it intelligent. There are many branches to Artificial Intelligence but in this paper we are going to deal with those branches which deal with prediction.

Pattern Recognition: When a program makes observations of different entities, it is often programmed to compare with a pattern stored. For example, a vision program may match eyes and nose pattern in a scene in order to find a face. These complex patterns require quite different methods than do the simple patterns that have been studied the most.

Timeline: Timeline is keeping account of the past values and predicting how the graph of any particular value has changed over time. Database as we know, is used to store data in the form of records in an organized way. A single entry or record can't fetch enough information hence the collection of records in the form of tables. Databases are built to facilitate the data storage, processing, and retrieval activities associated with data management in information systems. Today Databases Management System are used to create, backup and handle Databases for Knowledge Discovery Process, Data Mining etc. which account to the Decision Support System. Relational database management systems (RDBMS) were designed to solve a particular problem, store, manage and consult a large amount of data of same type - in opposition to KBSs, which are intended to extract useful knowledge from knowledge that is already represented and stored in database.

Intelligent Databases are the fusion of Databases with Artificial Intelligence which uses both KBS's and RDBMS to store, process and analyze data better. The term Intelligent Database was introduced in 1989 by the book "Intelligent Databases" by Kamran Parsaye, Mark Chignell, Setrag Khoshafian and Harry Wong.

\section{LITREATURE REVIEW}

Mrs. Neelu Nihalani et al has given several general approaches to $\mathrm{AI} / \mathrm{DB}$ integration and various developments in the field of intelligent databases have been investigated and reported in their paper.[2] Both DBMS and AI systems represent well established technologies, research and development in the area of AI/ DB integration is comparatively new. The motivations driving the integration of these two technologies include the need for

(a) Access to large amounts of shared data for knowledge processing,

(b) Efficient management of data as well as knowledge, and

(c) Intelligent processing of data.

N. Morari and S. Vlad presents some aspects regarding the joint use of artificial intelligence techniques for the activity evolution diagnostication and prediction by means of a set of indexes. [3]. For the diagnostication and prediction the following tools are used here: regression models, pattern recognition and multilayer perceptron. Their paper presents: REFORME software written by the authors and the experiments carried out in order to analyse the activity of BSE.

Fern B. Halper and Miklos A. Vasarhelyi deals with and proposes a program of research on database intelligence linking several areas of more traditional computer science research with management information systems [4]. Parsaye defined intelligent databases as "databases that manage information in a natural way, making that information easy to store, access and use." They defined three levels of database intelligence:

\section{i. intelligence of the high-level tools \\ ii. Intelligence at the user-interface level \\ iii. Intelligence of the underlying database level}

Their paper focuses on the second and third levels bringing in the prospective of not only computer tools and single site 
needs but the more general view and prospective of management information systems.

Xindong $\mathrm{Wu}$ presents a system structure for ILDB systems and discusses practical issues for ILDB applications, such as instance selection and structured induction. [5] An intelligent learning database (ILDB) system integrates machine-learning techniques with database and knowledge base technology. It starts with existing database technology and performs both induction and deduction. The integration of database technology, induction (from machine learning), and deduction (from knowledge-based systems) plays a key role in the construction of ILDB systems, as does the design of efficient induction and deduction algorithms

Jan Sundin and Ian Winchester try's to draw upon their experience, both to characterize databases of the kind useful to historians as they presently exist as well as to try to characterize what the next generation of databases might be like, namely, intelligent databases. [6] The present writers have been involved in the production and use of two historical databases, one in Canada (Winchester) and one in Sweden (Sundin). The Canadian database used mainly census records and assessment rolls at decade intervals. The Swedish database used mainly parish registers which give a near continuous record of census-like data.

Donald P. McKay et al gave a new interface called Intelligent Database Interface (IDI).The Intelligent Database Interface is a cache based interface that is designed to provide Artificial intelligence systems with efficient in access to one or more database on one or more remote database systems (DBMSs).The IDI provides artificial intelligence systems in general and expert systems in particular with efficient access to one or more databases management systems which support SQL. [7]

\section{ARTIFICIAL INTELLIGENCE}

Intelligence is the computational part of the ability to achieve goals in the world. Varying kinds and degrees of intelligence occur in people, many animals and some machines thus Artificial Intelligence is the study of human intelligence such that it can be replicated artificially.

Technically, Artificial intelligence (AI) is technology and a branch of computer science that studies and develops intelligent machines and software. Major AI researchers defined it as" the study and design of intelligent agents", where an intelligent agent is a system that perceives its environment and takes actions that maximize its chances of success. John McCarthy defines it as "the science and engineering of making intelligent machines". Intelligence is the computational part of the ability to achieve goals in the world.

The ultimate effort is to make computer programs that can solve problems and achieve goals in the world as well as humans.AI research is highly technical and specialized, and is deeply divided into subfields that often fail to communicate with each other. Some of the division is due to social and cultural factors: subfields have grown up around particular institutions and the work of individual researchers. AI research is also divided by several technical issues. Some subfields focus on the solution of specific problems. Others focus on one of several possible approaches or on the use of a particular tool or towards the accomplishment of particular applications.

According to strength, artificial intelligence can be divided into two sections: Strong Artificial Intelligence and Weak Artificial Intelligence

Strong Artificial Intelligence: machine-based artificial intelligence that can truly reason and becomes self-aware (sentient), either human-like (thinks and reasons like a human mind) or non-human-like (different form of sentience and reasoning) - coined by John Searle: "an appropriately programmed computer IS a mind"

Weak Artificial Intelligence $=$ machine-based artificial intelligence that can reason and solve problems in a limited domain. Hence it acts as if it were intelligent in that domain, but would not be truly intelligent or sentient.

\section{DATABASE}

A Database is an arrangement of organized data. It's an electronic filing system where all the physical data is transformed into records and stored for future use. Databases are used widely used in private and public sectors and their application depends on the requirement of the area of use. Different Data Models work towards building different types of Databases such as Relational Database, Cloud Database etc.

Database contains historic as well as present data which provides efficient and fluent use of the information stored for a variety of applications, this shared knowledge can be used to feed the decision support system and also help in quantitative and qualitative analysis of a particular field of a record.

Databases are built to facilitate the data storage, processing, and retrieval activities associated with data management in information systems. Database systems are significant in the implementation of data management

\section{INTELLIGENT DATABASES: INTEGRATION OF DATABASE AND ARTIFICIAL INTELLIGENCE}

Intelligent Database is an extension to our traditional databases, these are user interactive and apply artificial intelligence on three different levels of a database to form an advanced Intelligent Database:

The three levels of database intelligence are defined as:

i. Intelligence of the high-level tools

ii. Intelligence at the user-interface level

iii. Intelligence of the underlying database level

Intelligence at the high level tools is responsible for managing data quality and automatically discovering relevant patterns in the data with a process called data mining. This layer often relies on the use of artificial intelligence techniques like pattern recognizing, multilayer perceptron 


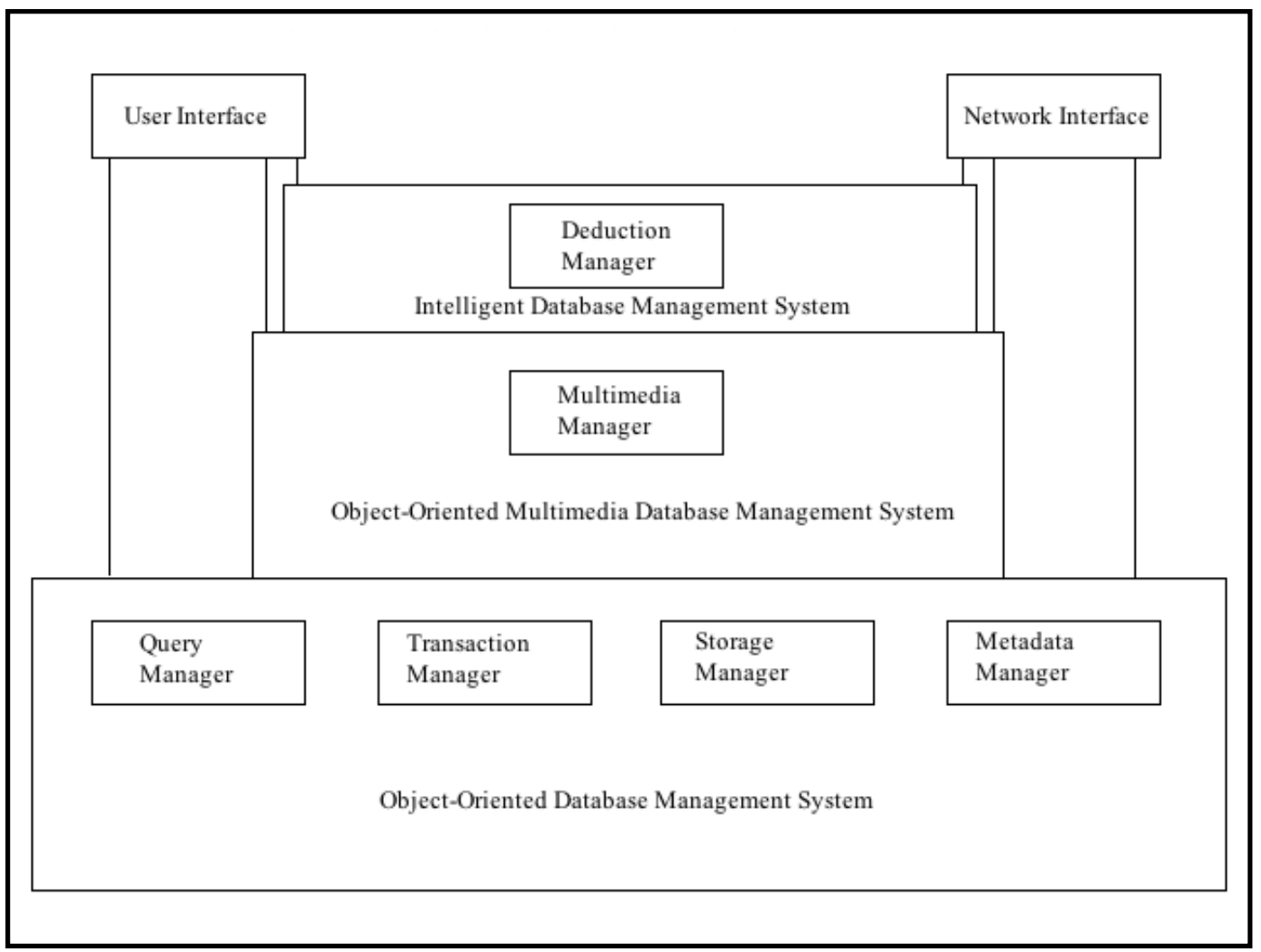

Figure 1: Architecture of Intelligent Database [8]

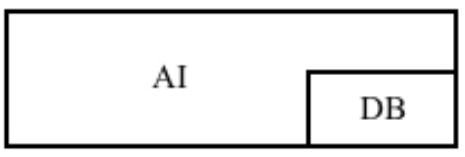

Extending the AI system

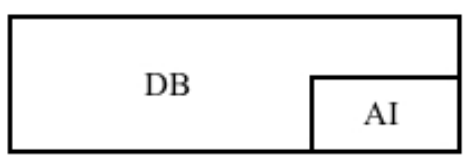

Extending the DB system

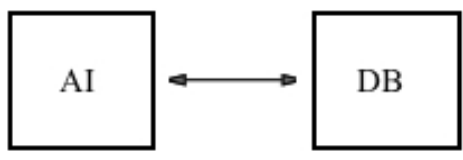

Loose Coupling

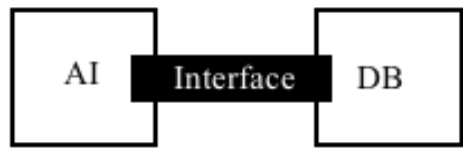

Enhanced $\mathrm{AI} / \mathrm{DB}$ interface

Figure 2 :Intelligent Database Interface [7]

Integrating Artificial Intelligence and Database for Intelligent Databases

Intelligence Database Interface (IDI) is a portable, cache based interface designed to provide artificial intelligence system in general and expert system in particular with efficient access to one or more databases on one or more remote database management system which support SQL

There are four approaches to for the integration by Intelligent Database Interface:-

Extending AI system to DB

Extending DB system to AI

Loose coupling between AI/DB
Enhanced interface between $\mathrm{AI} / \mathrm{DB}$

Extending AI system to $D B$

In this approach AI system with DBMS capabilities is extended to a Database to provide fast and efficient access and to manage the large amount of data stored in it. Here, the DBMS is not applied as a whole but in an ad hoc manner instead AI system is applied. Development of AI system application would require connection with a number of Databases which is extremely difficult to connect as the Data is frequently updated. 
Extending $D B$ system to $A I$

This approach is the complete opposite to the last approach, it includes a DBMS to provide knowledge representation and reasoning capability which are extended to AI, also in an ad hoc and limited manner.

The tools used are not sophisticated as the system of AI and no existing database connect to or the AI tools connect to the databases.

Loose Coupling between AI/DB
The Loose Coupling approach for $\mathrm{AI} / \mathrm{DB}$ integration is basically a simple interface between the two, it offers minimal support as the results are not satisfactory as per the integration and only works for light loaded databases and AI system.

\section{Enhanced interface between $A I / D B$}

This approach is more substantial and efficient than Loose Coupling $\mathrm{AI} / \mathrm{DB}$ as the interface is more rigid and performance is better. It provides a better interface and allows immediate advantage over the past technologies integrating $\mathrm{AI} / \mathrm{DB}$

Table 1: AI/DB Interconnection

\begin{tabular}{|c|c|c|c|c|}
\hline Sno. & Paper Title & Concept Used & Conclude & Source \\
\hline 1 & $\begin{array}{l}\text { Integration of Artificial } \\
\text { Intelligence and } \\
\text { Database Management } \\
\text { system: An Inventive } \\
\text { approach for Intelligent } \\
\text { Database } \\
\end{array}$ & $\begin{array}{l}\text { Reviewing several } \\
\text { approaches to the } \\
\text { integration of } \mathrm{AI} / \mathrm{DB} \text { for } \\
\text { building Intelligent } \\
\text { Databases }\end{array}$ & $\begin{array}{l}\text { An approach to the belief that one of } \\
\text { the main factors for the integration } \\
\text { lies in exploitation of the } \\
\text { equivalence between data models \& } \\
\text { knowledge representation in DB \& } \\
\text { AI respectively }\end{array}$ & $\begin{array}{l}\text { Neelu Nihalani } \\
\text { Dr. Sanjay Silakari } \\
\text { Dr Mahesh Motwani }\end{array}$ \\
\hline 2 & $\begin{array}{l}\text { The Joint Use of } \\
\text { Artificial Intelligence } \\
\text { Techniques for } \\
\text { Diagnostication and } \\
\text { Prediction }\end{array}$ & $\begin{array}{l}\text { Set of indexes are used } \\
\text { and analyzed using: } \\
\text { Regressional Model, } \\
\text { Pattern Recognition and } \\
\text { Multilayer Perceptron } \\
\text { on Bucharest Stock } \\
\text { Exchange }\end{array}$ & $\begin{array}{l}\text { The paper describes a method that } \\
\text { quantifies and represents the } \\
\text { evolution of prediction methods } \\
\text { using artificial intelligence }\end{array}$ & $\begin{array}{l}\text { N. Morariu } \\
\text { S. Vlad }\end{array}$ \\
\hline 3 & $\begin{array}{l}\text { Intelligent Databases : a } \\
\text { program for research } \\
\text { and development }\end{array}$ & $\begin{array}{l}\text { Intelligence at user } \\
\text { interface and underline- } \\
\text { database level is studied } \\
\text { to bring a prospective of } \\
\text { a more general view and } \\
\text { information } \\
\text { management system } \\
\text { using HIPM \& DPM }\end{array}$ & $\begin{array}{l}\text { Human information processing } \\
\text { model (HIPM) and data processing } \\
\text { model (DPM) are compared to get } \\
\text { an insight on the development of } \\
\text { intelligent database }\end{array}$ & $\begin{array}{l}\text { Fern B. Halper } \\
\text { Miklos A. Vasarhelyi }\end{array}$ \\
\hline 4 & $\begin{array}{l}\text { Building Intelligent } \\
\text { Learning Database } \\
\text { System }\end{array}$ & $\begin{array}{l}\text { Induction and } \\
\text { Deduction, operations of } \\
\text { data mining applications } \\
\text { are used to build } \\
\text { intelligent learning } \\
\text { database system }\end{array}$ & $\begin{array}{l}\text { Knowledge acquisition from } \\
\text { databases can be implemented with } \\
\text { Intelligent Learning Database } \\
\text { (ILDB) system tool }\end{array}$ & Xindong Wu \\
\hline 5 & $\begin{array}{l}\text { Towards Intelligent } \\
\text { Databases : or the } \\
\text { database as historical } \\
\text { archivist }\end{array}$ & $\begin{array}{l}\text { Two historians working } \\
\text { with different } \\
\text { perspective on census } \\
\text { records combined work } \\
\text { to characterize the next } \\
\text { generation of databases : } \\
\text { Intelligent Database }\end{array}$ & $\begin{array}{l}\text { Considering artificial intelligent } \\
\text { techniques into databases by } \\
\text { specifying general characteristics of } \\
\text { Intelligent Databases }\end{array}$ & $\begin{array}{l}\text { Jan Sundin } \\
\text { Ian Winchester }\end{array}$ \\
\hline 6 & $\begin{array}{l}\text { The Intelligent } \\
\text { Database Interface: } \\
\text { Integrating AI and } \\
\text { Database Systems }\end{array}$ & $\begin{array}{l}\text { Intelligent Database } \\
\text { Interface (IDI), a cache } \\
\text { based interface which is } \\
\text { used by artificial } \\
\text { intelligence system to } \\
\text { access one or more } \\
\text { databases. }\end{array}$ & $\begin{array}{l}\text { IDI is efficient, simple to use \& } \\
\text { provides a higher degree of } \\
\text { portability as it supports a variety of } \\
\text { AI applications which require access } \\
\text { to remote DBMSs and capability to } \\
\text { perform DBMS like operations. }\end{array}$ & $\begin{array}{l}\text { Donald P. Mckay } \\
\text { Timothy W. Finin } \\
\text { Anthony O'Hare }\end{array}$ \\
\hline
\end{tabular}




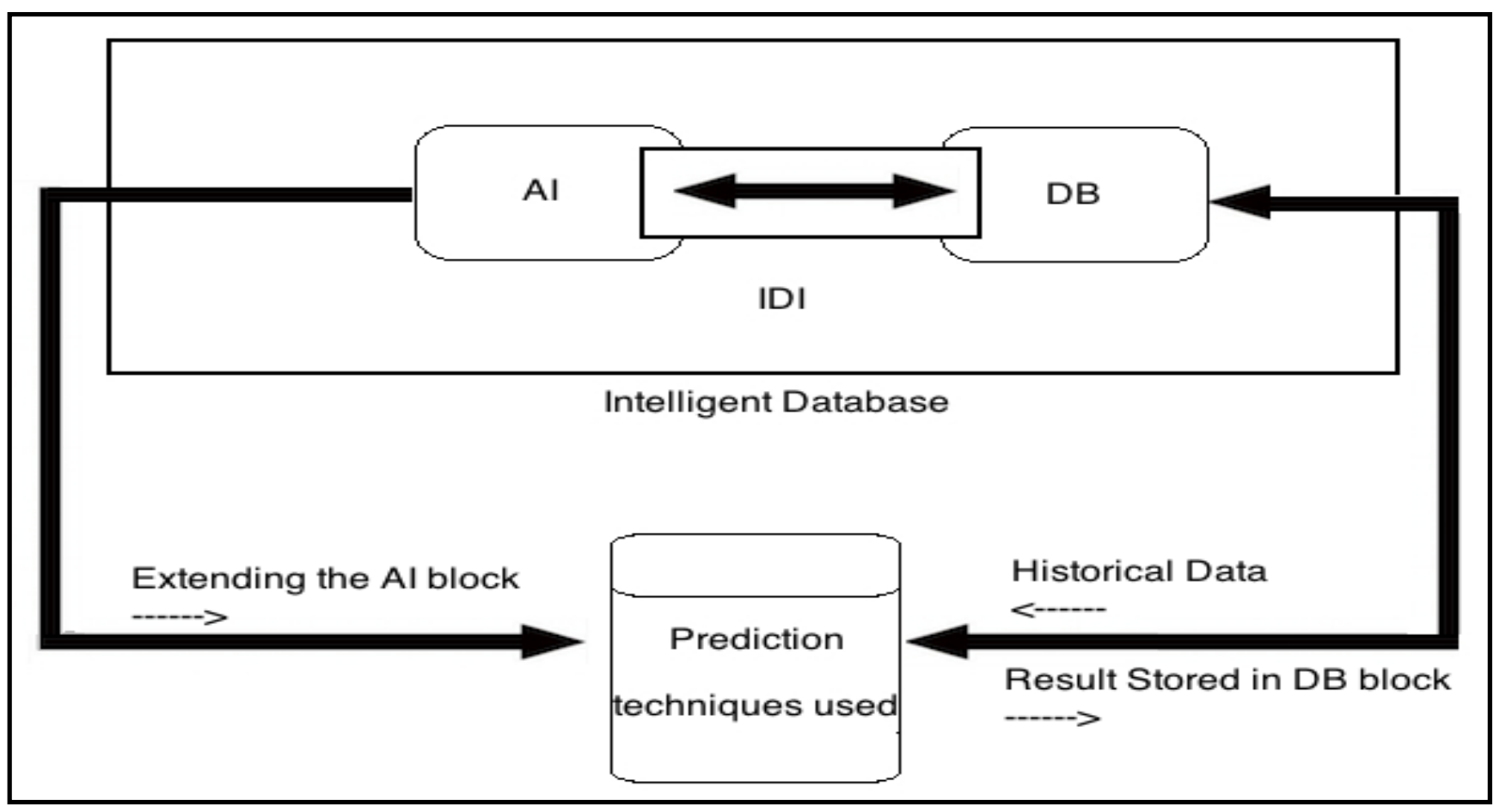

Fig. 3: Inter Connection of IDB with prediction via IDI

\section{CONCLUSION}

Prediction or Forecasting is about making a statement on how things would change or be in the future. These statements are based on knowledge and records, which can be fetched from Intelligent Database .In this paper we reviewed publishing's from different authors. Reviewing Mrs. Neelu Nihalani and others and concluded that for intelligent database, data mining and knowledge representation are the key factors. Fern B.Halper said that human information processing and data modelling processing are used to develop intelligent database Donald Mckay and others together gave interface of intelligent database. Different prediction techniques are analyzed and an evolution to prediction is represented by N.Murariu and S.Vlad Hence implying an intuitive approach for prediction using intelligent database. Using Artificial Intelligence prediction can be done based upon the historical data available with us at our database. The prediction is done with the combined use of artificial intelligence and databases giving us an intelligent database. The result can be stored in either same database or different for future prediction.

\section{REFERENCES}

[1] Turing, A."Computing Machinery and Intelligence", MIND, 1950 .

[2] Nihalani, N., Silakari, S., and, Motwani, M. "Integration of Artificial Intelligence and Database Management System: An Inventive Approach for Intelligent Databases". First International Conference on Computational Intelligence, Communication Systems and Networks, 2009.
[3] Morariu, N., and, Vlad, S. "The Joint Use of Artificial Intelligence Techniques for Diagnostication and Prediction”. Journal of Applied Computer Science, 2007.

[4] Halper, F.B., and, Varsarhelyi, M.A.,'Intelligent Databases: a program for research and development". Rutgers Accounting Research Center, 1991.

[5] Wu, X. "Building intelligent Learning Database Systems". AI Magazine Vol 21(3),2000.

[6] Sundin,J.,and Winchester,I., "Toward Intelligent Databases or Database as Historical Archivist".Archivaria,1982.

[7] McKay, D.P., Finn, T.W., and, O'Hare, A. "The Intelligent Database Interface: Integrating $\mathrm{AI}$ and Database systems",National Conference on Artificial Intelligence, 1990.

[8] Thuraisingham, B. "Integrating Intelligent Database Technology and Trusted Database Technology". Computer Security Journal,1992.

[9] Paulraj Ponniah. "Data Warehousing Fundamentals for IT Professionals" Wiley, 2010.

[10] Bertino,E.,Catania,B.,and,Zarri,G.P.,"Intelligent Database Systems"ACM Press,2001.

[11] Parsaye,K.,Chingnell,M.,Khoshafian,S.,and,Wong,H. "IntelligentDatabases",Wiley,1989. 